\title{
Non Communicable Disease Admissions in Developing Country as Experienced from the Medical Ward of a Tertiary Centre in Nigeria
}

\author{
Alikor Chizindu Akubudike*, Nwafor Chibuike Eze \\ Department of Medicine, University of Port Harcourt, Port Harcourt, Nigeria \\ Email address: \\ alikorchizindu@yahoo.com(A.C.Akubudike),c.ezenwafor@gmail.com (N. C. Eze) \\ ${ }^{*}$ Corresponding author
}

\section{To cite this article:}

Alikor Chizindu Akubudike, Nwafor Chibuike Eze. Non Communicable Disease Admissions in Developing Country as Experienced from the Medical Ward of a Tertiary Centre in Nigeria. Central African Journal of Public Health. Vol. 4, No. 2, 2018, pp. 34-37. doi: $10.11648 /$ j.cajph.20180402.11

Received: February 17, 2018; Accepted: March 24, 2018; Published: April 12, 2018

\begin{abstract}
Non-Communicable Diseases (NCDs) are chronic medical conditions that are non-infectious. NCDs which include a cluster of illnesses (Diabetes mellitus, Cancers, Chronic respiratory diseases, cardiovascular disease and musculoskeletal disorders) are increasing worldwide due to changing lifestyles and socio-economic status with significant contribution to the global disease burden. It is projected that by 2020, the largest increase in NCD deaths will occur in Africa which currently has a heavy infectious diseases burden. NCDs usually affect adults who are economically productive and bear enormous social responsibilities. The aim of this study is to determine the pattern of non-communicable diseases in the medical wards of the University of Port Harcourt Teaching Hospital (UPTH). It was a retrospective and hospital based study. The admission and discharge registers of the medical wards of UPTH from January 2013 to December 2016 were reviewed and NCD admissions extracted. There were 1096 cases of various NCDs constituting $57.7 \%$ of total medical ward admissions of 1898. The male to female ratio was $1: 1.2$ with a mean age of $54.40 \pm 21$ years. Subjects $\geq 50$ years of age accounted for $60.5 \%$ of total admissions. Diseases of the cardiovascular, endocrine and renal systems were found to be the most prevalent accounting for $46.5 \%, 18.8 \%$ and $12.4 \%$ respectively of the NCDs in this study. Hypertension and hypertension-related complications, diabetes mellitus, and chronic renal failure are major and important contributor to NCD admissions in the medical wards of UPTH. Early detection, appropriate management as well as patient education will play significant role in reducing its morbidity and mortality.
\end{abstract}

Keywords: Non Communicable Disease, Admissions, Developing Country

\section{Introduction}

Non communicable diseases (NCDs) is now considered as the leading cause of morbidity and mortality globally $[1,2]$. In the 2015 Global burden of diseases study, analysis of data on mortality, morbidity and risk factors from 1990 to 2015 in 195 nations showed that NCDs accounted for two third of all deaths [3]. While the proportion of death due NCD is higher in the developed nations the developing nations are much more affected in terms of absolute numbers. In 2005, NCDs was said to be responsible for 35 million deaths of which about $80 \%$ was in low and middle income countries [1, 2]. The rate of increasing prevalence of NCDs in the developing world has been fuelled by multiple risk factors and globalisation $[4,5]$. The World Health Organisation (WHO) western pacific regional committee recognised the critical impact of NCDs on mortality of about 30,000 daily in the pacific region and considered it a global threat to development [4]. Sub-Sahara Africa is in an early stage in the epidemiology transition still having a high incidence of infectious diseases and a rising trend of NCDs [1, 4]. In a study of all deaths at a referral centre in south west Nigeria, the researchers reported a reduction by half the death from infectious diseases, and a double trend of non-communicable diseases [6]. The prevalence of NCDs was found to be higher in the urban communities. The epidemiology transition with an increasing 
incidence of NCDs have been reported in other local studies [7-9]. The factors responsible for this trend include, the modernisation complex, aging demographics, change in nutritional habits, physical inactivity level, tobacco use and alcohol misuse $[4,5]$. WHO projected that deaths from NCDs which is likely to increase globally by $17 \%$ and in the Africa sub region by $27 \%$ will exceed deaths due to communicable, maternal, perinatal and nutritional diseases combined by 2030 [1]. In the Global Action to reduce the burden of NCDs, WHO targets $25 \%$ relative reduction in the risk of death from the leading NCDs by 2020 [10]. This work is done at the UPTH medical ward to check for the pattern of non-communicable disease admissions over a period of four years.

\section{Materials and Method}

\subsection{Study Area}

Study was conducted at the medical wards of the University of Port Harcourt Teaching Hospital Rivers State. The hospital is located in Alakahia and it's a tertiary referral centre. It receives clients from Rivers State and other neighbouring States of Abia, Imo, Bayelsa, Delta and Akwalbom. The Medical Wards are four wing wards in the third and fourth floor of the main hospital complex and has about 104 bed spaces equally distributed in the male and female medical wards. Main source of admission into the wards are the accident and emergency unit and medical outpatient department.)

\subsection{Study Design}

A retrospective descriptive study

\subsection{Study Population}

The study population include adult patients; 18years and above who have been admitted in the medical wards of the University of Port Harcourt Teaching Hospital between January 2013 to December 2017.

\subsection{Data Collection}

The admission and discharge register of the medical wards was retrieved. The records of all admission from January, 2013 to December, 2016 were collated from the registers. Information collated were the date of admission, age, sex and diagnosis. The diagnosis was classified into communicable and non-communicable diseases. The communicable diseases were sub classified into the affected body systems.

\subsection{Data Analysis}

Excel spread sheet was used to enter the data and statistical package for social science was used to analyse the data. The distribution and frequencies of the variables was examined and presented in charts. The analysis was to determine the prevalence of NCDs in the study population. The age distribution of those with NCD was categorised into seven groups along with the intra-category sex distribution. The percentage proportion of each system diagnosis among the NCDs was calculated. The calculated percentage proportions distribution was presented in charts.

\section{Results}

There were 1898 admissions into the medical ward over the study period of 4years.

There were 1096 cases of various NCDs constituting $57.7 \%$ of total medical ward admissions as depicted in figure 1. The mean age was $54.40 \pm 21$ years. Figure 2 showed that subjects $\geq 50$ years of age accounted for $60.5 \%$ of total admissions with male to female ratio of $1: 1.2$. Figure 3 showed the age and sex distribution of the NCDs which is found to be commoner amongst females across all age groups. Diseases of the cardiovascular, endocrine and renal systems were found to be the most prevalent accounting for $46.5 \%, 18.8 \%$ and $12.4 \%$ respectively of the NCDs in this study as shown in figure 4 .

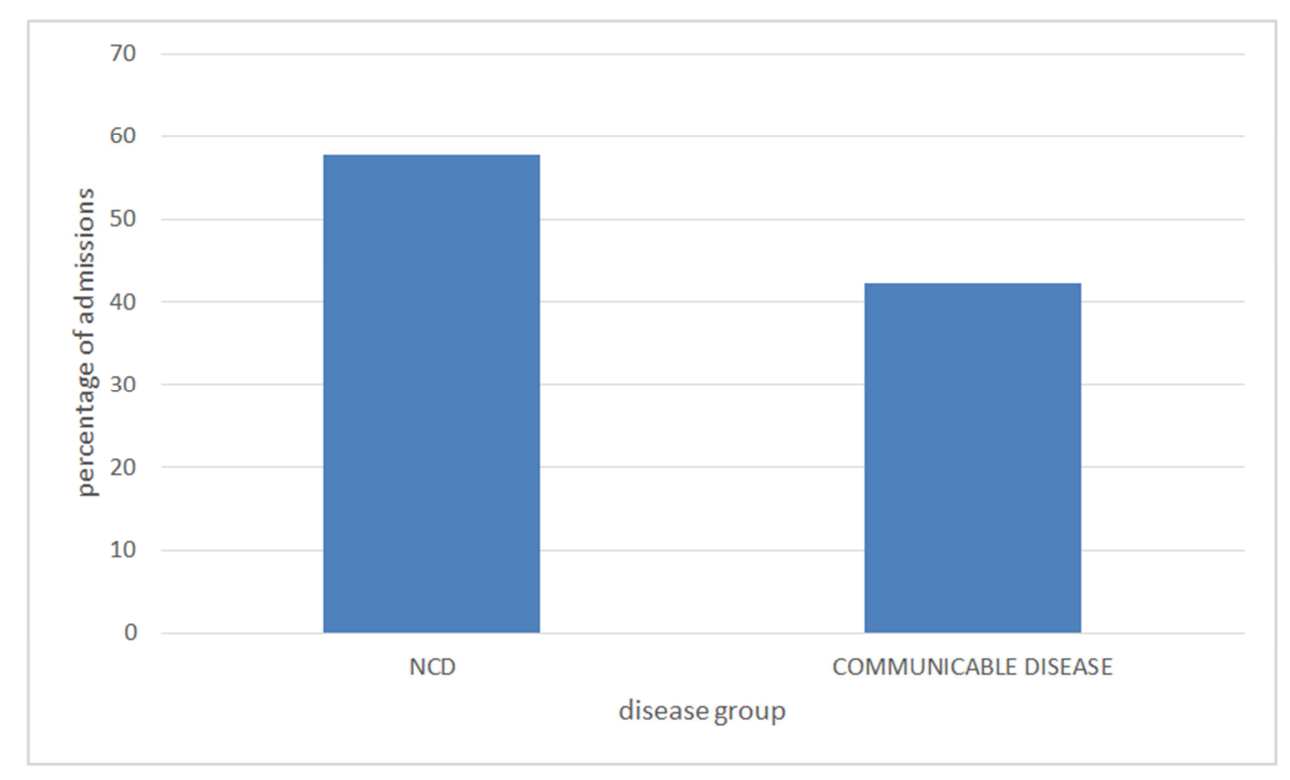

Figure 1. Admission pattern of disease groups. 


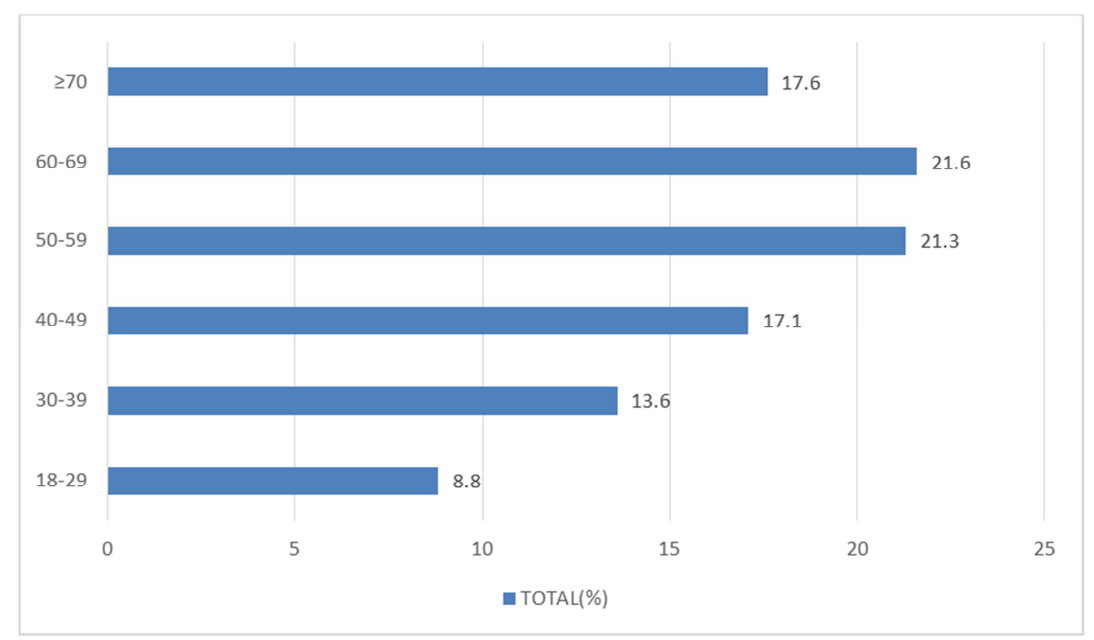

Figure 2. Disease distribution by age groups.

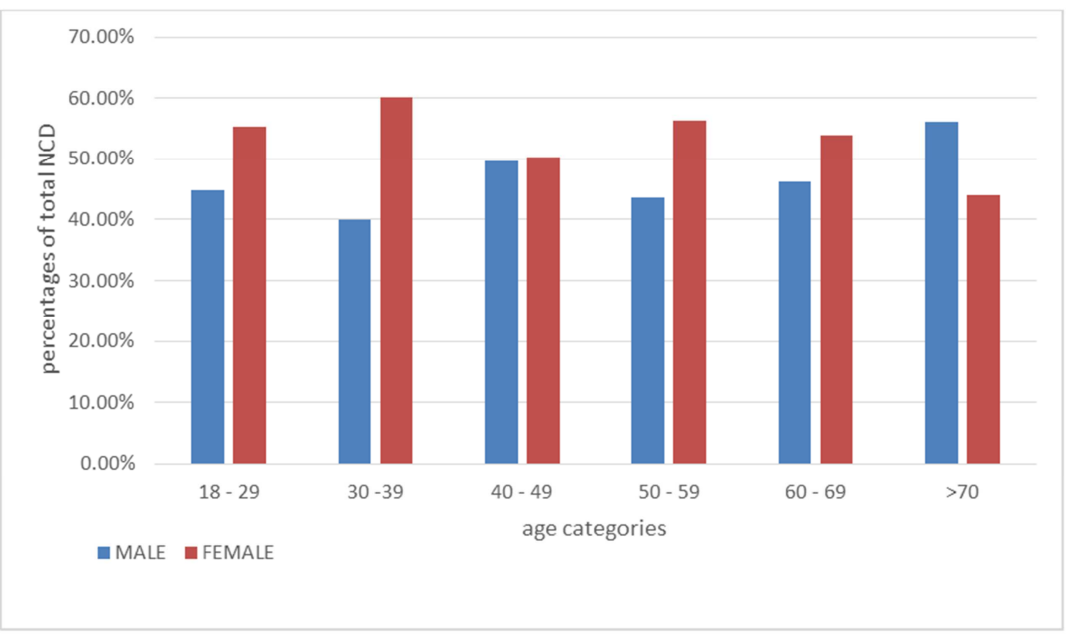

Figure 3. Age and Sex distribution of the NCDs.

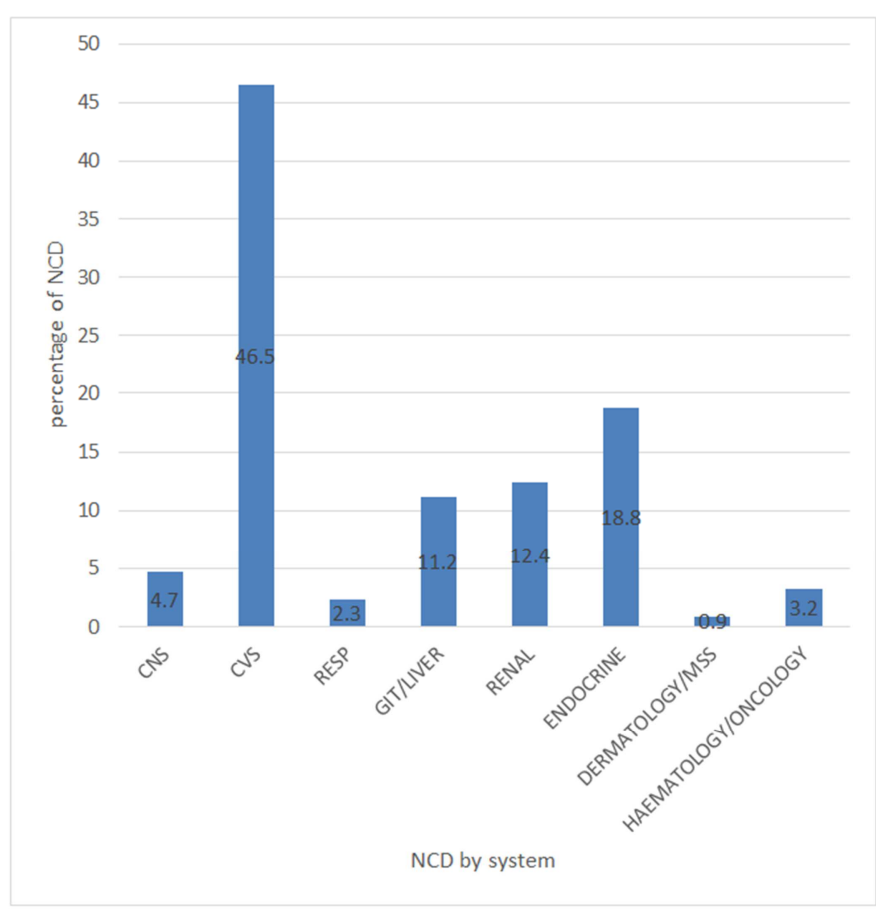

Figure 4. Distribution of non-communicable diseases by systems of the body. 


\section{Discussions}

NCDs constituted approximately $60 \%$ of total medical ward admissions in this study which is in keeping with the work reported by Unachukwu et al. in the same hospital about a decade earlier in which they found an NCD prevalence of $56.2 \%$ [7]. Similarly, a slightly higher prevalence of $68.4 \%$ was reported in another study among medical ward admission in a medical centre south west Nigeria [8]. All these are consistent with the deposition that Sub-Sahara Africa is in an early stage in the epidemiology transition with a rising trend of NCDs $[1,4]$. The increasing number of risk factors such as western diet, tobacco use, insufficient physical activity and high prevalence of other primary conditions like obesity and hypertension most of which are usually in clusters may help to explain this trend as increasing prevalence of NCDs in the developing world has been fuelled by multiple risk factors and globalisation $[4,5]$.

The mean age of subjects in this study was $54.40 \pm 21$ years with over $60 \%$ of NCDs reported in subjects fifty years and above similar to the global trend which showed increasing prevalence of NCDs with advancing age [3]. Advancing age is a strong non modifiable risk factor for most NCDs including hypertension, ischaemic heart disease, heart failure, diabetes mellitus, cerebrovascular diseases, chronic kidney disease, chronic respiratory diseases as well as cancers [4]. Other local studies are also in keeping with increased prevalence of NCDs in the older age groups [7,8].

Diseases of the cardiovascular system were the largest contributor to NCDs in this study accounting for nearly half of all the NCDs reported. Diseases of the endocrine and renal systems together constituted about a third of all NCDs in this study with the endocrine system diseases been the second largest cause of NCDs. Unachukwu et al reported same trend [7]. Work by Wachukwu et al found a renal disease prevalence of $15.4 \%$ in tandem with the renal disease prevalence found in this study [11]. Other works in tertiary centres in neighbouring south-east, Nigeria reported cardiovascular diseases as leading causes of medical ward admissions [9, 12]. These further buttresses the increasing burden of cardiovascular diseases and other NCDs in the developing nations which is related to changing lifestyles and in consonant with the epidemiologic transition concept in developing nations of the world.

\section{Conclusions}

Non communicable diseases account for significant cause of medical ward admissions in Port Harcourt, Nigeria and there appears to be an upward trend. Cardiovascular, endocrine and renal systems are the most affected systems. These with their attendant complications and chronicity place increasing big burden on the population already constrained by poverty and out of pocket payment for health care. The national health system that is already battered by high incidence of infectious disease, unstained or poor investment and rapidly increasing population with high morbidity will need to be strengthened. A lot of work remains to be done in all levels of health care; create more awareness on healthy living, reduce and or modify the modifiable risk factors and provide affordable health care. While we hope that government and heath facility managers will translate the result of this studies and others into policy statement, there is need to deliberately encourage community based studies for continuous surveillance not just of the disease but also of the risk factors and outcome.

\section{References}

[1] WHO African Regional Ministerial Consultation on Non communicable diseases www.who.int/nmh/events/2014/africa_ncds_background_pape r.pdf

[2] Ala Alwan David R. A review of non-communicable disease in low- and middle-income countries international Health, Volume 1, Issue 1, 1 September 2009, Pages 3-9.

[3] Mayor Suzan. Noncommunicable diseases now cause two thirds of death worldwide BMJ 2016, 355:54-56.

[4] Principle of Medicine in Africa $4^{\text {th }}$ edn. David Mabey et al published by Cambridge University press 2013.

[5] Maiyaki MB, Garbati MA. The burden of non-communicable diseases in Nigeria; in the context of globalization. Ann Afr Med 2014;13:1-1.

[6] Adeolu A, Arowolo O, Alatise O, et al. Pattern of death in a Nigerian teaching hospital; 3-decade analysis. African Health Sciences. 2010;10 (3):266-272.

[7] Unachukwu C. N Agomuoh D. I, Alasia D. D Pattern of diseases among medical admissions in Port Harcourt, Nigeria Nigerian Journal of Clinical Practice March 2008. Vol 11(1):14-17.

[8] Ogunmola OJ, Oladosu OY. Pattern and outcome of admissions in the medical wards of a tertiary health center in a rural community of Ekiti state, Nigeria. Ann Afr Med 2014;13:195-203.

[9] ke SO. The pattern of admissions into the medical wards of the University of Nigeria Teaching Hospital, Enugu. Nigeria Journal of Clinical Practice 2008;11:185-92.

[10] Sparling PhilipB, HowardBethany J, Dunsten David W, Owen Neville: Recommendation for physical Activity in older Adult BMJ 2015;350:h100 www.bmj.com/content/350/bmj/100.full

[11] Wachukwu CM, Emem-Chioma PC, Wokoma FS, Oko-Jaja RI. Pattern and outcome of renal admissions at the University of Port Harcourt Teaching Hospital, Nigeria: A 4 years review. Ann Afr Med 2016;15:63-8.

[12] Ukpabi OJ, Uwanurochi K. Comparing indications for cardiovascular admissions into a Nigerian and an Israeli Hospital. Ann Afr Med 2017;16:70-3. 